\title{
Italia 2090. Post-Urban/Super-Urban
}

Laura Mucciolo*1[0000-0003-3460-493X]

${ }^{1}$ Department of Architecture, School of Architecture, 50121 University of Florence, Italy

\begin{abstract}
The significant put in crisis related to city, coupled to the renewed attention in confront of extra-urban context (inner territories), has rekindled the spotlights on countryside, as to semi-inhabited land, even to re-encode. This research is proposed to foreshadow a possible interpretative key on next future's inhabit (under specific conditions), in the light of some visible changes which have already flourished in the Now, by using project as checking exercise of theorical research. Verona is scientific test bench, in which dualism city-countryside vanishes to the advancing of the wide and dense definition of «post-urban landscape». A vegetal-built basement, that radiates its tentacles in open/not-bound field, renewed cathedral protectress of life and evolution, structured (with project's rules) with Super-Cartesian layers giving rise to a Hyper-rational mesh, jeopardized from obsessive and frequent interference. Chameleon monoliths, fixed objects in Continuous Movement as paradoxical reply to mutual adaptation's dwelling, in which «not the strongest will survive, but the most suitable». This ability to adaptations is the key point on tomorrow's questions, according to inhabiting as a form of «stamina», without that the rigid streamlining reduced dwelling to legislative and tabular count; but, going back to crucial questions involving, will always involve, the first and the last man. Psychedelic spatiality in which techè, shape and response line up in restless and controversial out-of-scales, as skeletal membranes. SuperArchitectures, as total tool for life's governance, unusual and redundant, last devices that translate culture and society's knowledge.
\end{abstract}

Keywords. Architecture, countryside, post-urban, landscape, hydroponic technics.

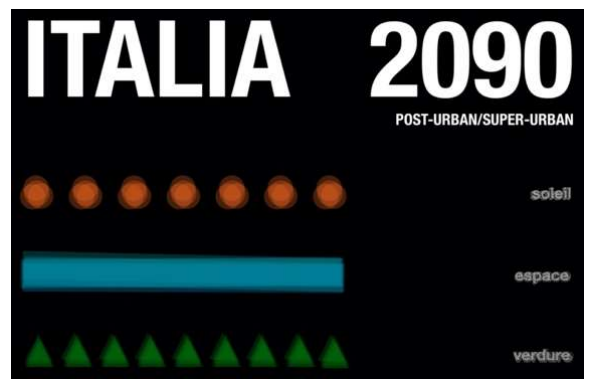

Fig. 1. ITALIA 2090: a non-conventional Manifesto. ${ }^{\circ}$ Laura Mucciolo.

${ }^{*}$ Corresponding author: mucciololaura@gmail.com 


\section{Introduction}

\subsection{City}

In 1982 Bogdan Bogdanović* publishes Gradoslovar [Dictionary of town terminology], aiming to clarify through a list what are the words which one defines the city by. Four hundred lemmas of various origins try to explain the manifold nature of urban space. Four hundred words, arranged in four enclosures by one hundred each don't follow a logical order of structure; the only bond to highlight the one that connects start and arrival: first word is «tool», last «stable»; this random placement identifies two moments. City has been $a$ tool to be touched and detracted by necessity, to be settled and functional as a machine, to be carefully cutted into pieces if uneuseful, city has been a movement; however it has been thought as «tool as» but not - in power - in itself, and so, «adept to» ${ }^{\dagger}$. City has also been $a$ dwelling, cultural transposition of a living statement, role that, according to contemporary conditions, must be revalued. It is then, in the relation that starts with the object, the tool, on the way to the spatiality, the stable, hoping to find the proper link between, that research will move on. Tool corrodes itself; space corrodes us. In this consumption road, what will remain about city?

\section{To stop, to dwell - where shall we do this and how? - This is still the question.*}

Urban space, or better, its evolution represents the future bet on which architecture should hazard hypothesis: what's left, therefore, of urban space as design of dwelling space? Dwelling space is not exclusively the urban space, however the constant discussion on the architecture of the city has stifled the presence of a wide surrounding (extra-urban), that more or less, re-start to rumble. The central point of this research will not be to investigate when city started to dominate against the extra urban territory, or when the research focused its energies to the city's field, or more, when we have forgotten the extra urban as potential dwelling space. Instead, the point will be the possible alternative we adopt to live in.

\subsection{Safety machine}

Today, what is the body of the city? The answer comes from the legacy that Modern movement carries along: new contemporary considerations [4] rank at the core of beliefs on

\footnotetext{
*Bogdan Bogdanović (Belgrade, 1922-Wien 2010), graduated from the Department of Architecture and Engineering of the University of Belgrade. After a brief worker experience, he became a university professor at School of Architecture (he would waive it for political implications and protests, which he attended). He would base the Informal School of Architecture, operating since 1976 until 1990. At the $16^{\text {th }}$ Mostra Internazionale di Architettura La Biennale «Free Space» directed by Yvonne Farrell and Shelley McNamara (Grafton Architects), Serbian Pavillion would be dedicated to Citissary and to the project's research on city by Bogdanović, the entire Pavillion exhibition. Cf. [1].

‘ «Technology cannot be reduced at creation or using tools. Technology is metaphors' creation. By the time we create a tool, we make a form to a certain interpretation of the world that, one reified, is able to produce a certain effect on the world. [...] Its effect is such a shift, a relocation, but at the same time a decoupling; a certain way of thinking has been externalized and dismantled on tools, where there's no need of thinkers to activate. [...] It is said that, when you got a hammer, anything could be a spike. But that means don't operate the hammer» in [2], p. 22.

$\ddagger$ «Stable or Augian Stables. Our own. There’s a considerable gap between the concept of «living» and the category «to live». To stop, to dwell - where shall we do this and how? - at least for now, when compared to the insignificance of our free will, this decision is still with the complete or overwhelming power of invisible gods of economics, statistics, technology and their demons - machines are here primarily to dig earth and crush stones, and to do jobs that are difficult and painful for a man, and maybe they are unworthy of it - that is, they are here to help us clean our own Augian stables. Further on, they are in no case among us to make amphorae, or to play organs instead of us, or to bless our homes instead of our own hands. Perhaps machines are really needed so that we can dwell and settle down, although I am increasingly beginning to doubt this conditional need - but in order to live, the human hand has to bless and support the holiness of the home. Have you ever seen a machine blessing? » Cf. [1], p. 168; Also [3], s. p.
} 
Modern's project, a distress: a body fathomed with radiography and anatomy, a body which composition (throbbing and blooded) was unaware, it returns to be the mission of architecture to fight against the tuberculosis bacillus (historically defined as «consumption»» disease for its symptoms).

The disease discovered by Robert Koch in 1882 (hence the name Koch's bacillus) showed, among the causes of pneumonitis (at the earliest stage of phenomena, when still the responsibility for illness wasn't belonging to the bacillus): sedentary lifestyle, nasty air circulation in buildings, poor lighting). For a misunderstanding, tuberculosis starts to be considered as disease of «wet space» created by the bad design government of cities, overcrowded, soiled.

Starting from the spreading of this illness, Modern movement offered its «image» to deal with it, selling grammar's strongholds of project design (in contemporary, built-in and outdated, clearly to renegotiate) and a etymological dictionary «specific» and «geared» as assets instruments useful to prevention and healing from tuberculosis: pilotis that detach house from soil (latter's considered «wet, damp, space where illness reproduces itself» ${ }^{* *}$, the roof of the building as flat solar roof/roof garden to practice exercises of physical training or sunbathing. Always under this condition, appear clear the connection that leads LC to narrate the project for Ville Radieuse accompanied by a series of board with some different computed tomographies of pneumonic lobes ${ }^{\dagger \dagger}$. For the same reasons, «diagnosis» lemma is used to narrate and communicate the project, that it is, in Vers une architecture, we find:

The diagnosis is clear. Engineers make architecture. [...] People still believe, here and there, in architects, just as people blindly believe in doctors. ${ }^{*}$

Essentially the debate around an historical change generated from unknown illness, is played on the dwelling space, which acts as scenography. On the one hand, cities with old rotten and teeming houses, on the other hand a new advertising dwelling space: a safety machine. «Modern» movement house welcomes «modern» and wholesome bodies, it's not just about to protect who lives in but to contemporary generate an imaginary proposal: it's not just about the project, but the whole alternate architectonic scaffold (made of writings, films, scripts, music, athletic activities and propaganda), to support the design approach proposals. Dwelling space, with its safety devices, reveals itself as main «narcotic» tool for individual security from outside. In the contemporary, house ${ }^{\S}$ surrounded in the wider community of cities, has gone from being narcotic tool to attractive device: from numbness to a dark electrification, created by forced captivity. Clearly it has continued its role of «buffer» device than the unhealthy outside but has revealed how fallible and inadequate ${ }^{* * *}$ is the city as dwelling way (densely layered).

\footnotetext{
${ }^{\S}$ It is curious to note that, words used by Bogdanović for describing city are the same two linked to «consumption»: «Tool corrodes itself, space corrodes ourselves».

** «wet, humid ground, where disease breeds», in [5], pp. 55-56.

${ }^{\dagger}$ Reference is made to illustrations on Le Corbusier, The Radiant City, (1967), cf. footnote 5.

${ }^{\dagger}$ Cf. [6], p. 7.

${ }^{\S}$ Understood as «safe» space in which protect themselves from potential infections.

${ }^{* * *}$ It should be noted the significance and avant-garde position of B. Colomina, which refers to «sick building syndrome»: «The type of architecture that was meant to inoculate its occupants against disease has become a source of disease. We are becoming allergic to building. New bodies will probably have to be designed. A new theory of architecture is likely to follow» Cf. [4], p. 184.
} 


\section{Materials and methods}

\section{1 «Where did the cows go?»: exhibition as material, research as method}

Typing in Google's image search bar «countryside», we come across a uniform colors palette, most frequently: green (RGB: 96,132,134), blue (RGB: 68, 140, 172), yellow (RGB: 230, 184, 117). Generally: an undefined green stretch, the existence of abandoned infrastructural equipments for pedestrian traffic or based on traction agricultural machinery, the placement of wooden fences between two distinct properties or between road and field, the color of the sky is constantly verging to light blue, in its possible flavors/variants, matched by sun and clouds. Typing in search bar of website-archive by OMA ${ }^{\dagger \dagger}$, the word «countryside», the first result is a lecture held by Rem Koolhaas in 2012, with a black and red world map.

Starting from C.I.A.M.**, passing through Las Vegas [7], until the A Retroactive Manifesto for Manhattan [8], the catalytic converter of architecture has completely focused its own thoughts on urban space, on cities, on their possible futures, indeed ignoring something: the myth of infinite city, always bigger, always to create, re-create, re-produce. Essentially, «history of modern movement architecture coincided greatly with history of modern movement city» [9, p. 2].

The only representation is the urban one: trying to give a real definition of countryside, we wouldn't be wrong if we considered it as the undefined space (with no idea of neither density, extension, sizes), which we come across on the way towards the city, out of the city. This attention against cities has produced a huge amount of data on urban phenomena, the mightiest conquest is the conversion of intangible data in objects: maps, atlases, postcards, photos, research, films, memories. Half world's population, indeed, lives in cities; other half in countryside ${ }^{\S \S}$, «ignored» space, to be «re-coded»; because of forgetfulness, we ignore countryside configurations, in the here and now, extraordinary articulated but by no means, uncataloguable ${ }^{* * * *}$.

In other times, materials and methods, they'll be boundless travels in the seizure of unknown lands to map. Today, the length of voyage match with seconds that allow us from computer starts to research in Google Maps or Earth. The trip is gone, data is certainly according to dimensions and semblance: the easiness takeover, the immediacy representation, they affect negatively the space metabolism of knowledge.

The OMA world map significance was truly this, to challenge a mapping of ignored spaces and finally ${ }^{\dagger \dagger \dagger}$ highlight it as a problem. Those cartographies reveal an utterly reverse space: to the bucolic idealization that combines the fence to tumbleweed, are opposed

\footnotetext{
†'From OMA's website: «OMA is an international practice operating within the traditional boundaries of architecture and urbanism. AMO, a research and design studio, applies architectural thinking to domains beyond». The Office for Metropolitan Architecture was founded by da Rem Koolhaas, Elia Zenghelis, Madelon Vreisendrop, in 1975. The current partners' establishment is: Rem Koolhaas, Ellen van Loon, Reinier de Graaf, Shohei Shigematsu, Iyad Alsaka, David Gianotten, Chris van Duijn, Jason Long.

W.I.A.M., short for Congrès Internationaux d'Architecture Moderne, are Congresses created to promote functional both architecture and urbanism. First meeting took place in 1928 in La Sarraz (Switzerland). During the XI Congress in 1959, in Otterlo (Netherlands), members decided to stop carrying out the work.

$\$ \$$ The publication referred to United Nations «World Urbanization Prospects» (2018) https://population.un.org/wup/DataQuery/ - according to the number of countryside's inhabitants is 3401511, instead the number of city's inhabitants is 3901498: the difference is only in 500000 inhabitants.

****Anthony Quigley's photographer (anthonyquigley.com, on Instagram: @anthonyquigley), has been investigating satellite images, many of which describes the countryside. Notice that the coloration's photo data appears highly contrasted, with enhanced saturation compared to how they appear in reality; it is recommended to compare the photo data with the one given in Google Maps or Earth Pro (Maxart technologies, 2020).

HitI should be advised that territory as «question» has been guessed by L. e O.M. Ungers. In the book, [10] they deepened the manifestation of a Commune as a dwelling modality, also according to the diffusion ability in USA. This book [10], has been used by AMO/Samir Bantal and Rem Koolhaas as exhibition material in Countryside, The Future, Exhibition at Guggenheim Museum, New York, 20 February 2020-15 February 2021.
} 
automated objects made of repetitious configurations, to nuke the identity concept. Expanses boundless of solar panels, city-garden with regulartt* patterns, oil wail, greenhouses fields, salt pans, all of those articulated with a planimetric representation developed at 0 grade compared to «form» question. Form articulation works in contrast: if in the city, the form coincides with the localization, in the countryside the form becomes the resolution with generating identification: it does happen that similar or same configurations, they are at different latitudes, generating ubiquity. Those configurations don't show identity but icon of reference, «Landscape A as Landscape B», adopting similitude as design instrument, translating it in a mechanical copy and paste method. With other words, city is whimsicality, countryside can only be pure cartesian science, in fact super-cartesianism ${ }^{\S \mathcal{S} \delta}$.

\subsection{Countryside for images (Beta Archive): digital cartography as material, exploration projects as method}

The investigation divided into configurations tries to give back a consideration about the manifestation modalities of some specific and general characters, advanced before using spots.

1. The building of countryside space is based on layering. The very first level welcomes the building of drawing space, based on the «0» element, and repeated a number of times such as to satisfy the project requirements. Those basic elements assembled define one of the possible configurations, with which the countryside could be composed;

2. Countryside appears inhabited by a series of objects closely related and dwelled by at times - by humans.

A mapping research (implementable, hence Beta Archive) about diffusion and presence of those configurations highlights some issues:

1. Configurations' diffusion is uniform and apparently, they aren't governed by a doseresponse bond easily identifiable;

2. Configurations, according to the mentioned above, don't represent the identity character of the landscape, indeed, they generate a compositional structure which uses the similitude as instrument of project (Landscape A-Form A as Landscape B-Form B);

3. Again, according to the mentioned above, configurations organize the landscape according to a dynamic of copy and paste (copy and paste architecture);

4. Countryside's planning is a hall of mirrors: it surely exists a «0» type configuration that gave rise to the subsequent, but the ambiguous and uncontrolled spread of configurations doesn't allow us to recognize it (please consult the section « 8 » for more on diffusion);

5. The configurations' multiplication, observable from satellite, makes the countryside appear as pattern landscape, heterogeneous but classifiable;

6. Pattern's architecture provides the landscape a reverse status, compared to the urban space. Cities are articulated, among the many, for elevation's development: a section is able to describe the relationship that links a man and an object; for countryside, the planning organization is perfectly evident from satellite;

7. The ruling architectures of those spaces are controlled by a clear settlement planning that rules out the urban whimsicality: Cartesian landscape is countryside (rawcartesianism/hyper-cartesianism).

\footnotetext{
㨆Extraordinary and terrifying is the Datong Panda Power Plant: a solar park of 100 MW power, in Yongshencun prefecture, China (3958'32.1"N 11329'04.2"E).

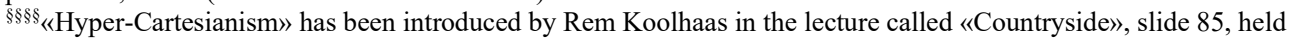
on 25 April 2012, at Stedelijk Museum Amsterdam, in opposition to urban "whimsicality». It should be noted that this phrase did not appear in the exhibition, replaced with «raw cartesianism». Here the lecture to which reference is made - https://oma.eu/lectures/countryside, retrieved 10 April 2020.
} 
Those considerations, coming in from the countryside's observation, daring, they describe a pattern articulation of landscape, which diffusion is ruled by a grid-computing based level of interconnection, where pattern isn't epitome of identity but repeatable and adaptable configuration, structures made with copy and paste method, which outcome is the similitude as design material.

Project, possibly encountered, is recalled to directness realization, apparent camouflage of technical-formal responses, shiftable reproduction. Countryside is reverse space, also for the scaling size in planning, there's no section or façade.

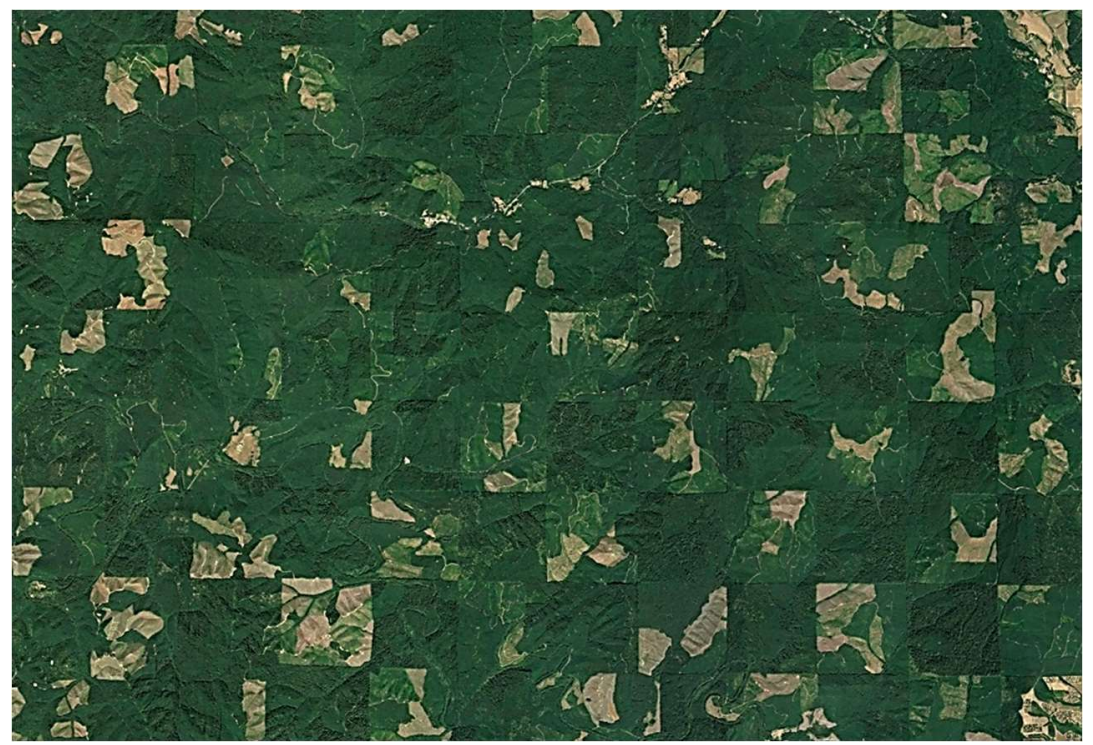

Fig. 2. $43^{\circ} 50^{\prime} 46.9^{\prime \prime} \mathrm{N} 123^{\circ} 24^{\prime} 43.5^{\prime \prime} \mathrm{W}$; Crow-applegate-lorane $\mathrm{Sd} 66$, Oregon, United States; RHWQ+G5 Alma, Oregon, United States. (C) Google Earth, Maxar Techonologies, 2020.

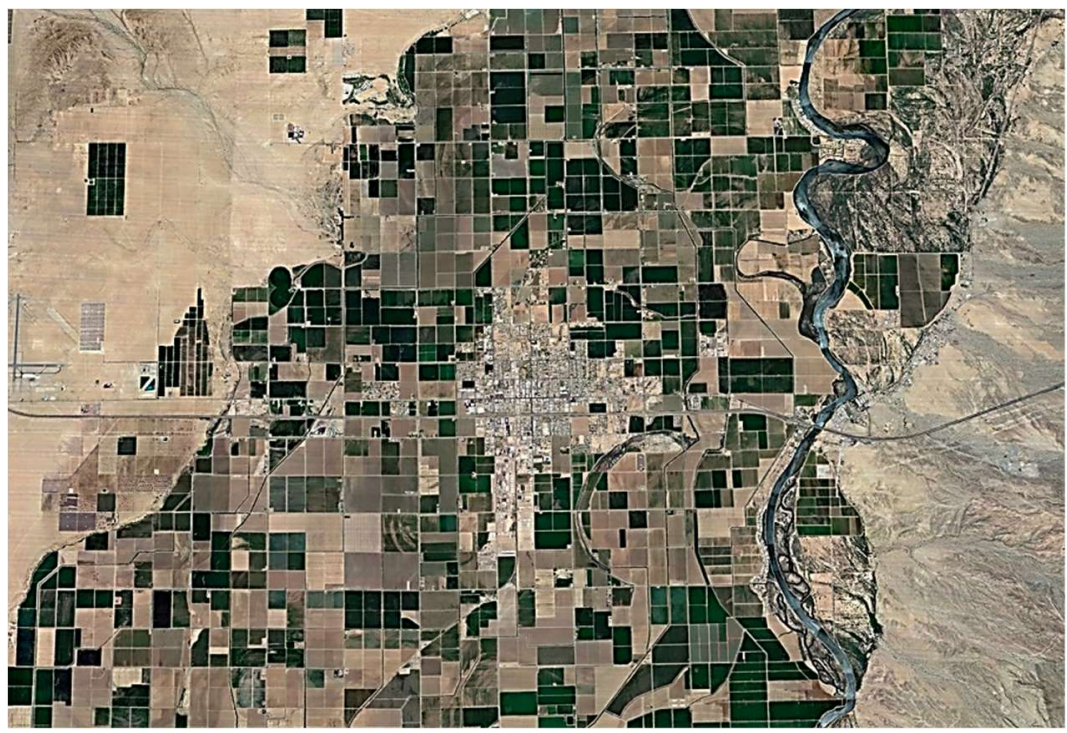

Fig. 3. 33 $32^{\prime} 54.6^{\prime \prime} \mathrm{N} 114^{\circ} 38^{\prime} 06.0^{\prime \prime} \mathrm{W}$; Palo Verde Unified School District, California, United States; G9X8+92 Miller Farms, California, United States. ${ }^{\circ}$ Google Earth, Maxar Technologies, 2020. 


\section{Results}

\section{1 a case study: Italia 2090}

\subsubsection{Verona 2090: Post-Urban}

Project's space starts with the matrix construction of forest, through the base unit multiplication (a square): the geometric link arises from measurements and relationship with the city, with the native mesh of settlement of the old city's Roman centuriation $(78 \times 78 \mathrm{~m})$; the network that articulates forest comes from the proliferation (three times) of the founding relation, in which every square took shift to lattice foot traffic ( $6 \mathrm{~m}$ each). The forest unfolds in an all-pervading way, crossing and multiplying in the open field, that leads from Cason del Chievo, proceeding tangent to the edge of Brenner highway, passing residue-free San Massimo, fully occupying the Brenner junction moving forward the city's walls border, again crossing doubly Adige River, invading Porto San Pancrazio, arriving at the extreme board of San Michele. The Forest crosses the whole surrounding, leaving uncovered, as happen in crackles, tracks and paths that have contributed to hierarchize this settlement.

This composition, meant as copied tiles different from each other, presents some meddling in the structured weaving.

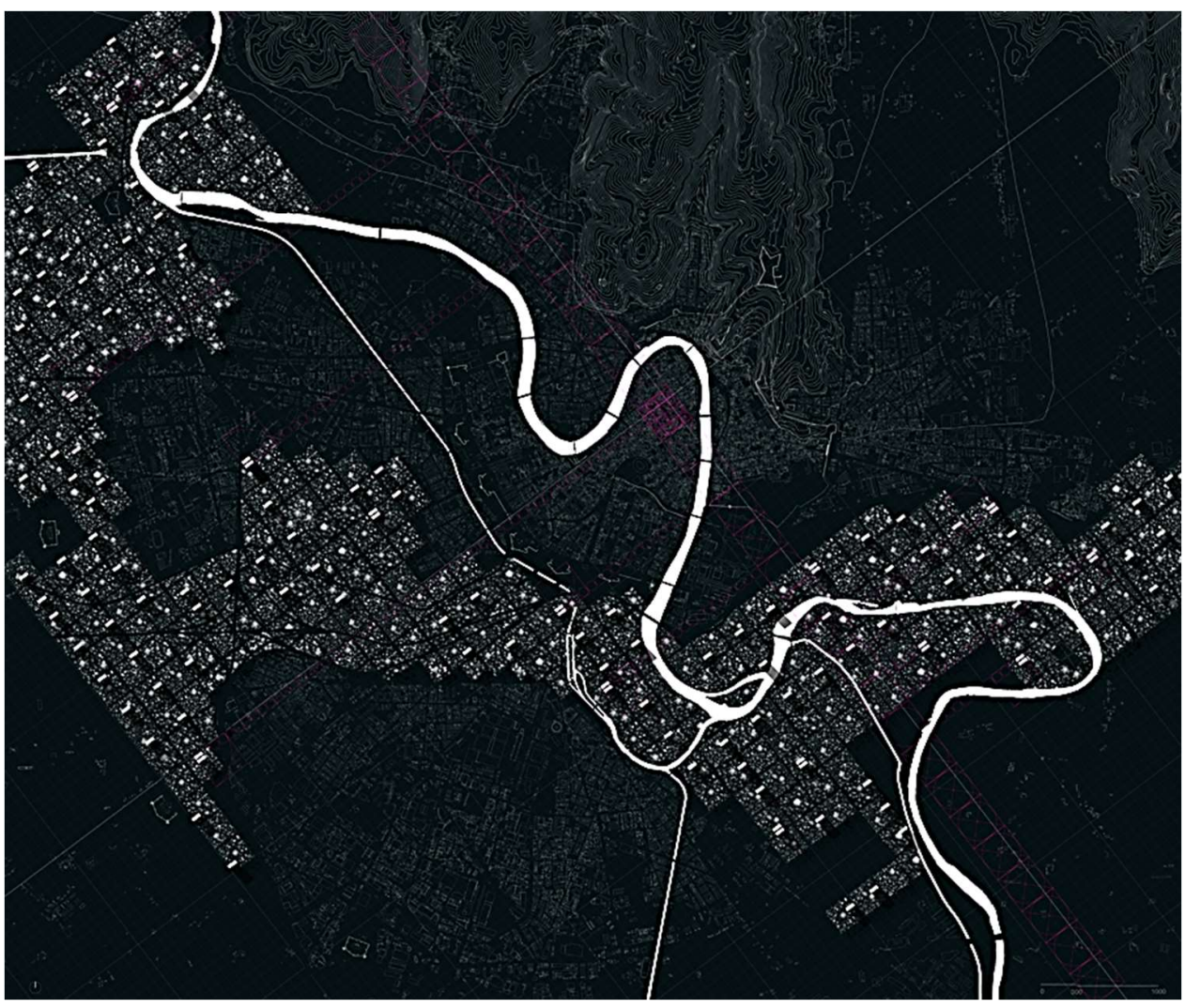

Fig. 4. Copy and paste forest: masterplan (1: 20000) of the built forest, see 3.1. ${ }^{\circ}$ Laura Mucciolo. 


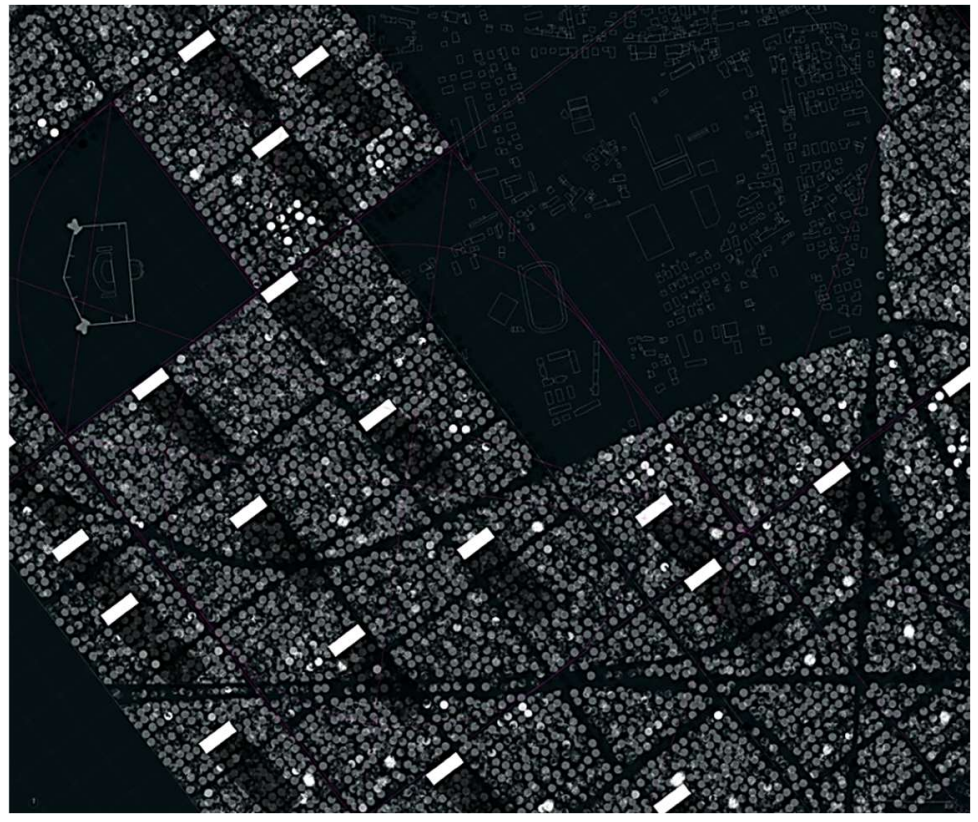

Fig. 5. Copy and paste forest. Masterplan detail (1: 5000), see 3.1. ${ }^{\circ}$ Laura Mucciolo 3.2 Verona 2090: Super-Urban.

The intrusions mentioned above are chameleonic objects, by turriform shape with one dimension predominant on the other $(77 \times 27 \mathrm{~m})$, which role is to transpose (in height) the practices hosted in countryside, in extension. The forest stands in relationship with towers according to one-fifth proportion.

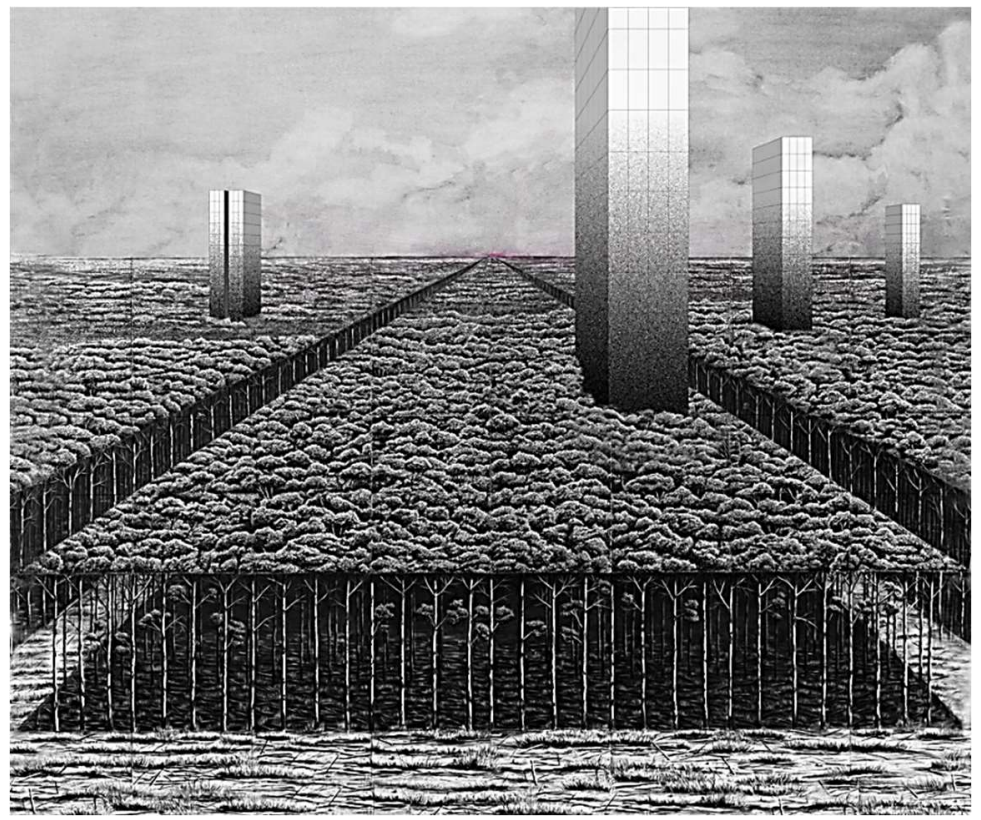

Fig. 6. Through the forest. The built vegetal basement and towers-system. ${ }^{\circ}$ Laura Mucciolo. 
Each tower is exactly the same as others: to confirm this rule, some towers constitute the twin-barrel variation, made with the combination of two single tower. However, the ratio is the same. The cultural environment that mentored those towers according to structure and formal results, is the replication (the possibility of replicate of each part of the entire whole tower), the chosen material, among those which admit best report between yield and form, and consequently, the dry assembling as junction rule.

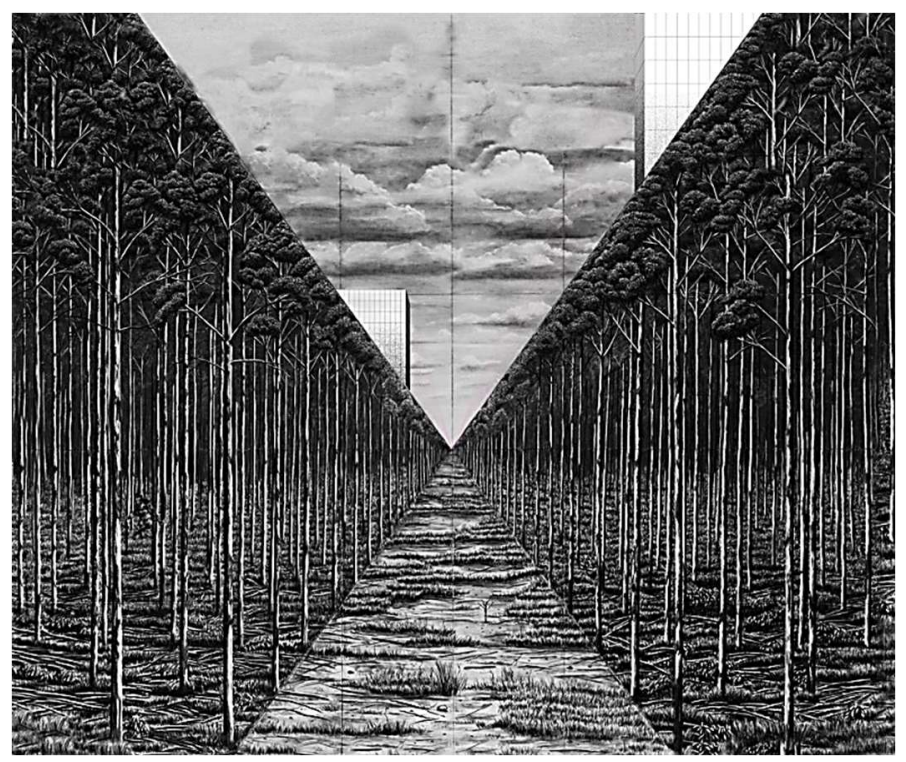

Fig. 7. Through the forest: «Where's Wally: Yeti edition». ${ }^{\circ}$ Laura Mucciolo.

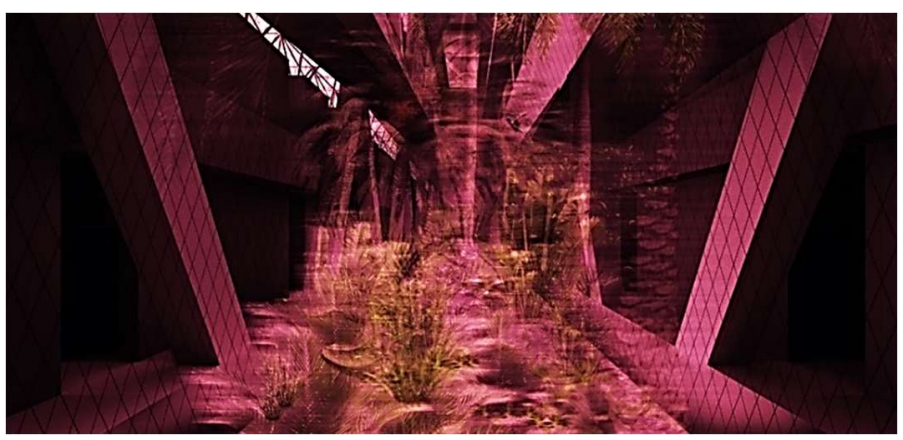

Fig. 8. Through the tower: Room of Plants, see 3.2. (c) Laura Mucciolo.

Each tower is held by a steel structural core [11] which is bearing frame. The skin is an electric surface: multiple steel serial structures, supported by diagonal braces anchored to the tower structure with anchor plates, they support mirrored panels for energy production to power the tower itself. The towers represent the replied multiplications in the form of highrise of one level kind: the access through a ramp $(53 \times 1.20 \mathrm{~m})$ that unfold in the central void of the tower $(53 \times 4.5 \mathrm{~m})$; at some points (third, fifth, eighth, tenth, twelfth level), the central void space is occupied by hanging gardens ${ }^{* * * *}$, which diverse variety, should be found in their natural habitat, at ground level or bush level.

\footnotetext{
${ }^{* * * * *}$ According to size and range as for the Room of Plants by Studio Vogt in Forum 3. The Novartis Campus project in Basel by Diener\&Diener Architekten (with H. Federle and G. Wiederin) or like garden project by P. Oudolf for the court of Serpentine Gallery Pavilion (P. Zumthor, 2011).
} 
This Room is living part of the space, for its continuous variation: for chromaticism (flowers and leaves' colors), for smells (growth, decay, wet), for scale (some plant species ${ }^{\dagger \dagger \dagger \dagger \dagger}$ raise themselves for different levels of tower, therefore by walking the ramp their complete growth may be understood). Each type of the level assumes a replicable configuration: alongside the void (sometimes it is occupied by the hanging garden) are placed the structures which characterize that level; perpendicularly to the void two elevator shafts are placed which fully cross the tower-shape (from zero to third level). The articulation of each level is arranged with the section which brings together the activities carried out in the specified structure-tower. The zero level is the one exceeding in height compared to the other levels. The first floor has been called «Cassandre's floors»: four axes of black mirrored monoliths (each one 3,6×1,2×7 m); every totem is a transducer of live-power in energy-power: through the Ais' programming able to absorbe the human's information, knowledge, evaluations, memories, choices, decisions, and to translate them (in terms of communication) and to switch them (in terms of voice-output). This level proposes a changing point of view on the epilogue of life (biologically aimed) as the end of existence, by proposing alternatively the energetic survival. The human (still human) could interact (input) with ancestors (commuted into energy) through his voice, and in exchange he will listen a similar sound near to the original one, likely but not accurate, which could bring back messages and code signs (output).

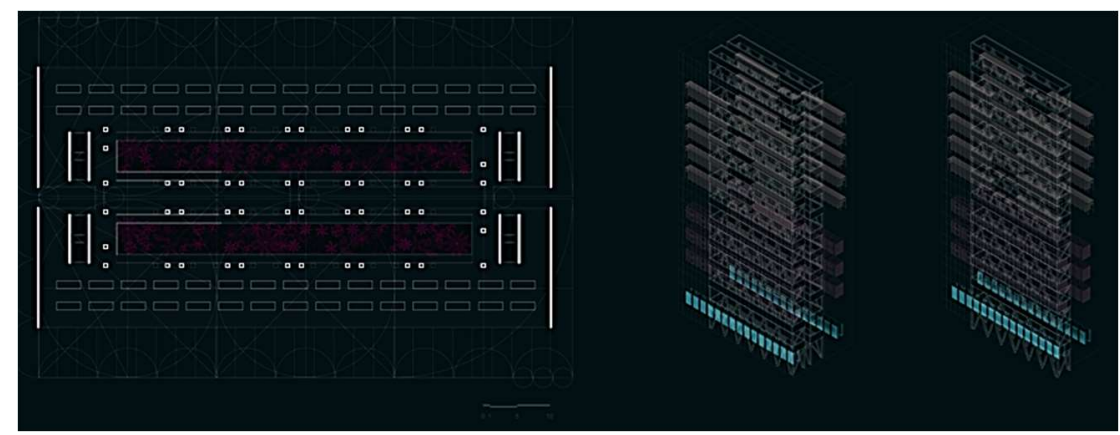

Fig. 9. Through the tower: Transductors' level and axonometries, see 3.2. ${ }^{\circ}$ Laura Mucciolo.

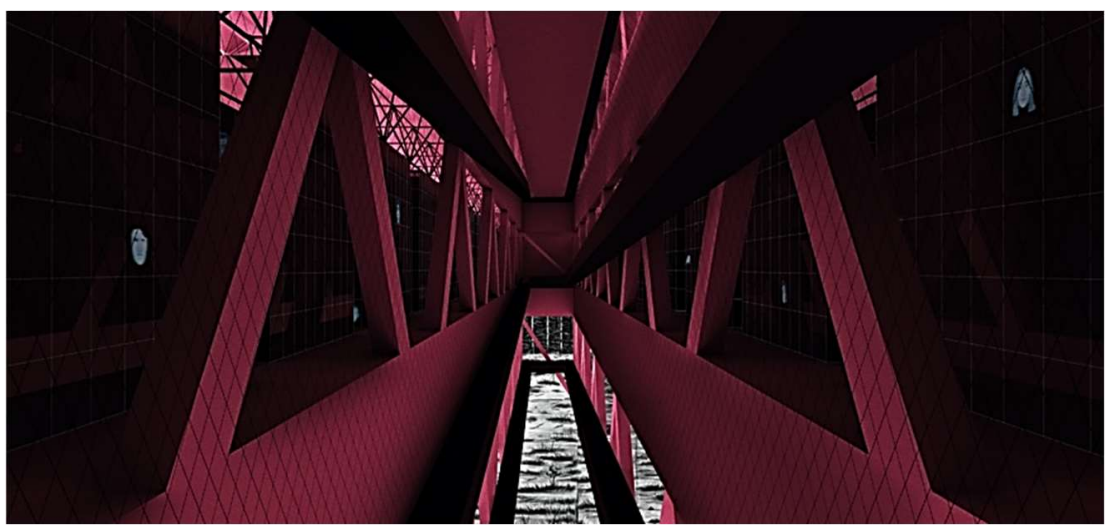

Fig. 10. Inside the tower: Transductors' level, see 3.2. ${ }^{\circ}$ Laura Mucciolo.

\footnotetext{
${ }^{\dagger+t_{\dagger}}$ Among species we find: Acoelorrhaphe wrightii (Madeira's palm), Adonidia merrillii (Manila's palm), Archontophoenix alexandrae, Arenga engleri (Formosa palm), Bismarckia nobilis, Brahea armata (Blue Mexican's palm), Butia capitata (Jelly’s palm), Chamaedorea radicalis, Latania loddigesii, Livistona muelleri (California's palm), Rhapis excelsa, Sabal causiarum (Puerto Rico's palm), Trachycarpus martianus, Bambuseae Kunth ex Dumort.
} 
Cassandra, Apollo's priestess, received as gift the prophecy ability, often remaining unheard. In this project, this level is the «Cassandre's floors» for the same reasons.

The second, the sixth, the thirteenth levels, they don't host any activities. The third, the fourth, the fifth levels are occupied by minimum modules $\$+$ for dwelling. This dwelling design should be read as minimum possible dismountable settlement dedicated to " $55+$ inhabitants», meaning this as anthropological and social thought for a critical side (the lack of interest in dwelling spaces for aged population). The dwelling space for the Third age is such a controversial field of research, in which it has been tried to refuse the palliative perspective, the admittance or the forced welfare ${ }^{\S \S \S \S}$, as the only admitted strategy; indeed, trying through the project a dwelling manner both community and individual at the same time which could give back to the « $55+»$ population [14] a cultural and personal scope (as a task). This level is organized on two parallel axes, each of which, is developed on two identical levels, related each other with a secondary system of ramps at the front and rear of the axes. Each axis of the dwelling space is structured with a canonical rhyme: wall, dwelling cell, services, and wall. Each dwelling cell develops itself with three different layers of density with the employment of integrated wall-systems, with the eventuality of a double occupancy: the access in the super-private zone (night area), an intermediate level used for (all day area and nourishment transforming area), an extra dwelling-cell loggia (to use as extension of the said cell), relationship space through exterior and interior.

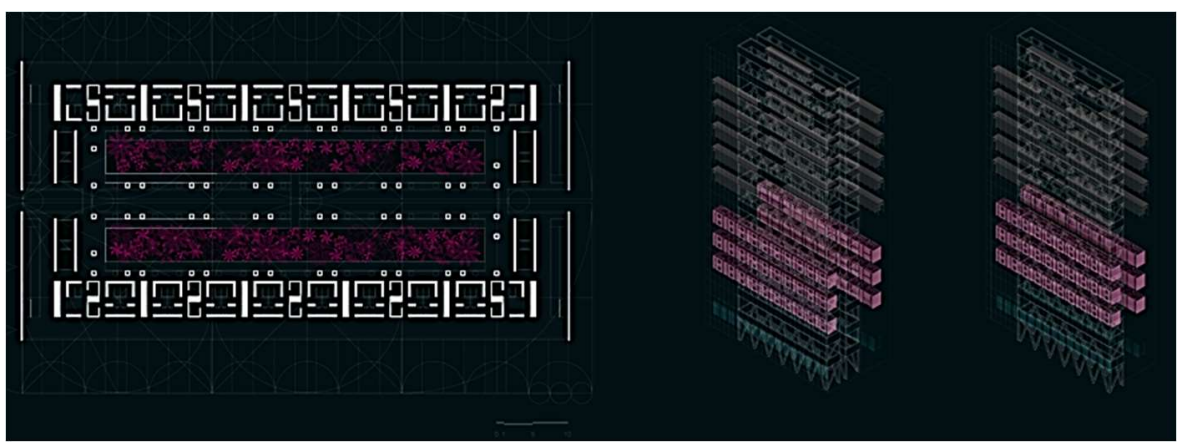

Fig. 11. Through the tower: Dwelling cells level and axonometries, see 3.2. ${ }^{\circ}$ Laura Mucciolo.

From the seventh to the eleventh level, the organization of space is devoted to the employment of hydroponics machines for the production of agricultural products; each one level is composed starting from the fourfold repetition of one production pathway. Each chain is composed with germination and sowing area (18 square meters), cultivation area ( 98 square meters for 5 levels), packaging area, as well as additional needed areas for necessities and laboratories (87 square meters). Those levels are to be considered as a cultural shift in the contemporary panorama, because of the usage of technical progress in the land-treatment. In this proposal, the traditional known link (land cultivation with human-engine techniques) is cancelled while promoting the alienated re-proposal of land (a lush and rich placenta of water and nourishing substances), in which the cultivation of fourth range products is grafted, which fast growth is speeded up by the pervasive magenta lights.

\footnotetext{
 residential models of our society. At the same time, have been studied the functional relationship between men and various furnishing components as to establish a series of best standard measures for the proper design, production and use, to be adopted inside of cubic boxes called rooms», cf. [13], pp. 144-159.

Meaning those viewpoints clearly sharply, in this project the dwelling unit design has been revived, related to specific wishes and demands of «55+» population, excluding prioritization of any kind.

$\$ \$ \$ \S$ Obliviously when it clearly doesn’t represent the only one possible alternative.
} 


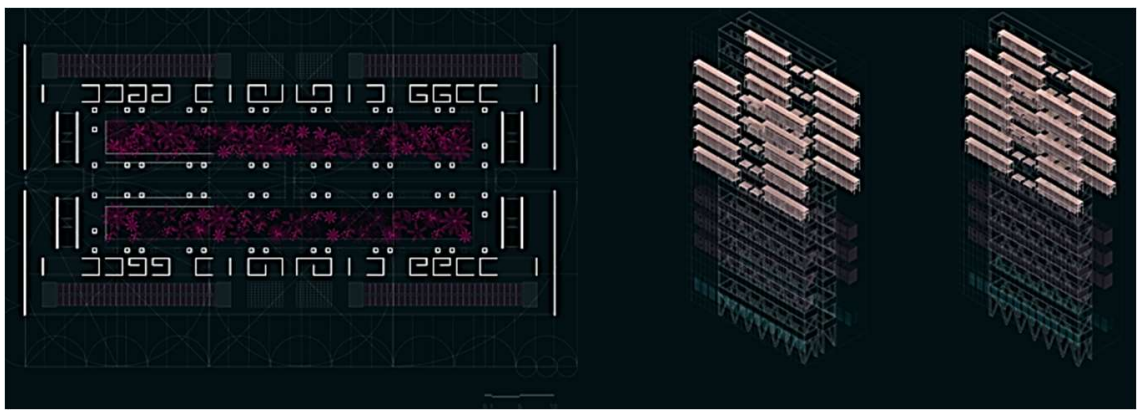

Fig. 12. Through the tower: Hydroponics machines level and axonometries, see 3.2. ${ }^{\circ}$ Laura Mucciolo.

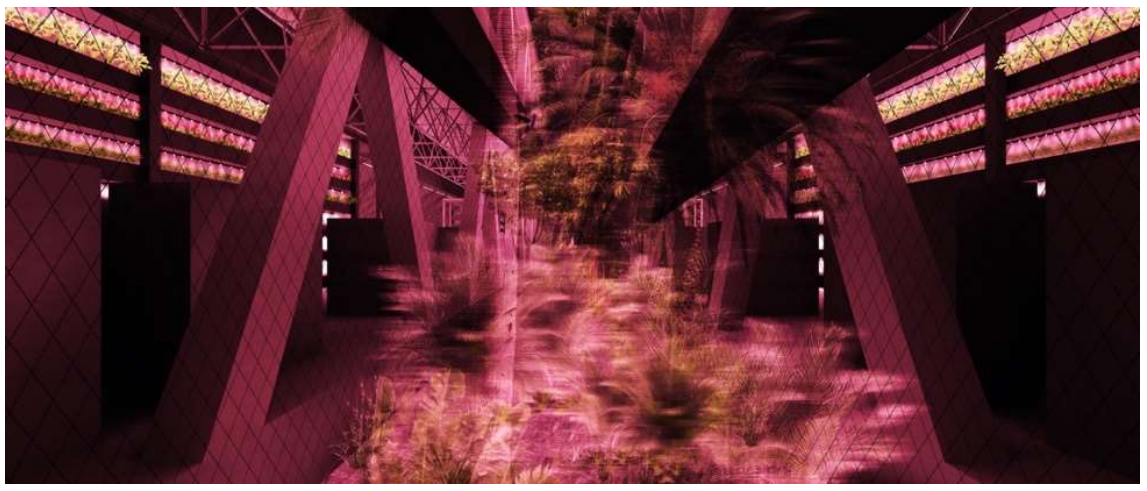

Fig. 13. Inside the tower: Hydroponics machines level, see 3.2. (C) Laura Mucciolo.

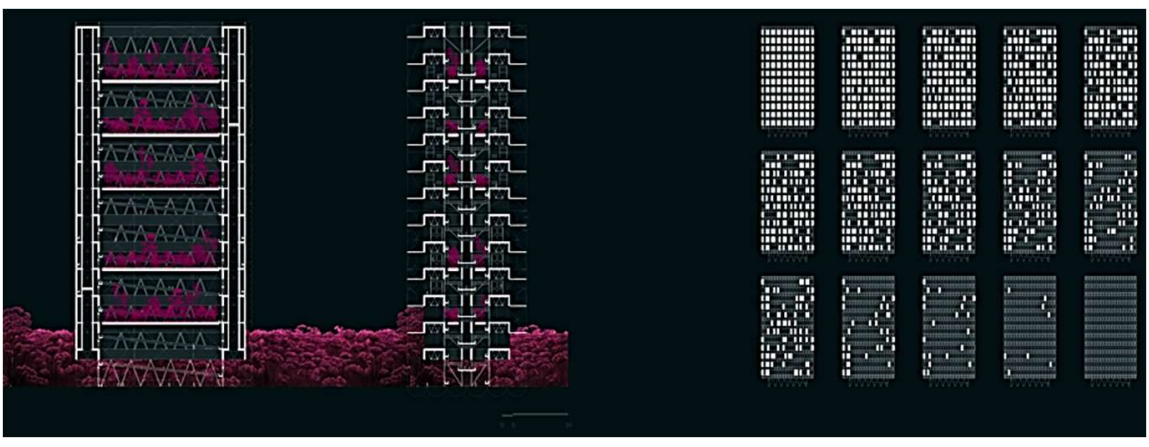

Fig. 14. Through the tower: Sections and façade disposition, see 3.2. ${ }^{\circ}$ Laura Mucciolo.

It occurs, basically, two trades. First, properly formal. The water (although enhanced) takes the place of soil, the sun takes the color of Magenta ${ }^{* * * * * *}$, the final product is a «scientific» one. The second trade is a paradigm shift. The «formal» transformation carries along one equation not properly balanced: the excess in this formula lies in the ability of (re)produced nature to be a little more: mighty, thick, mechanic, balanced. This plus contribution is a latest summary of this project: to dwell the Planet Earth towards long-term prospect it means to research enriched items, according to the application of technical

\footnotetext{
****** Magénta color is the nuance of the led light, which function as trial accelerator for crops growth. Within the spectrum, they are shown for this task the purple, green and blue lights; yellow light doesn't affect growth, taste and quality (they are employed significantly less than others); Luca Locatelli has photographed establishment crops (hydroponic or not), mostly in Netherlands, capturing exactly the changes of using lights.
} 
processes resulting from the advancement of science, in support of some pressing necessities (increase in population, increase in nourishing, means of survival, increase of dwelling space for everybody, soil protection, self-sufficient in energy).

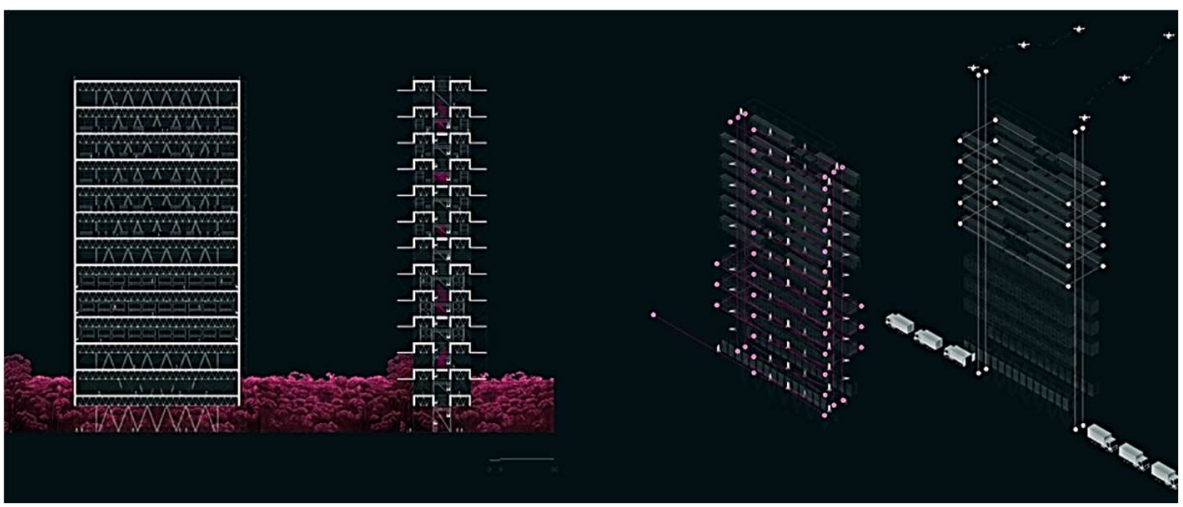

Fig. 15. Through the tower: Sections and axonometries schemes of distribution, see 3.2. ${ }^{\circ}$ Laura Mucciolo.

\section{Discussion}

\subsection{Italia 2090, super-urban: for whom?}

The first inhabitants of this «post-urban/super-urban landscape» are the specific range of users, socially accepted and indicated as «aged population», which in this research has been considered and usually re-called with the phrase $\langle 55+\rangle$; in this way a brave hazard has been indicated, the moment corresponding to the update of the senior's condition, which coincide with the anticipation of the socially accepted age for being considered as such.

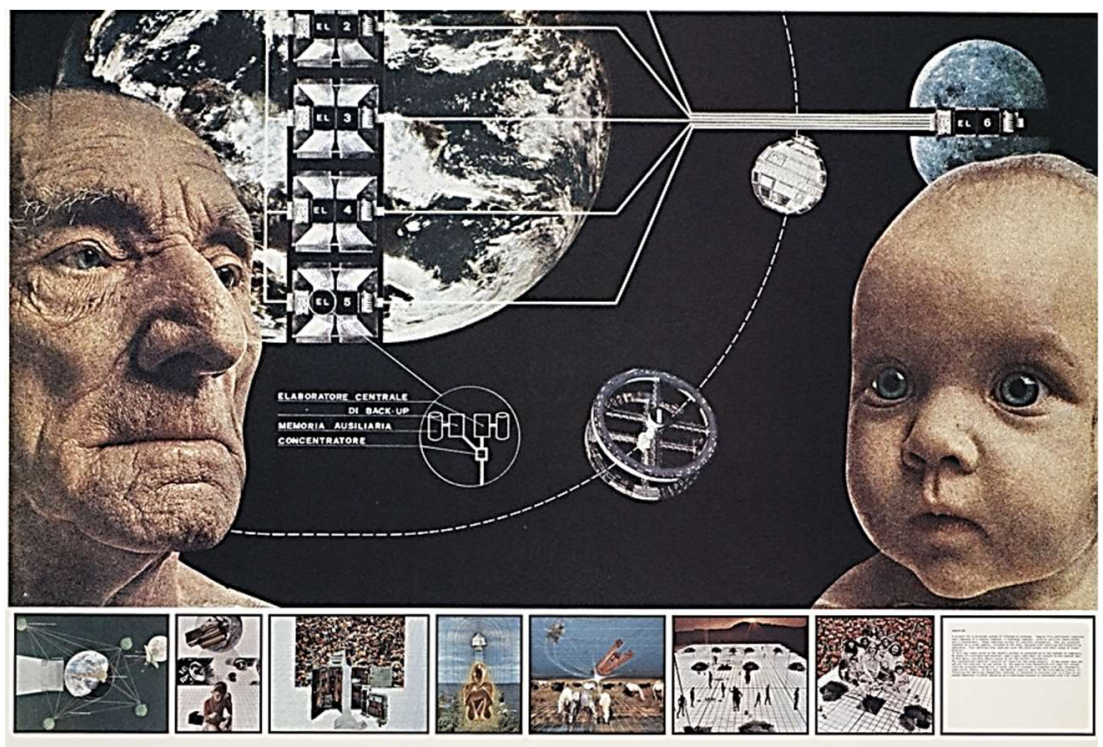

Fig. 16. Gli Atti Fondamentali, Educazione (Progetto 1), Superstudio 1971, 1973. Litography, 70×100 cm. Collection: MAXXI, Museo Nazionale delle Arti del XXI secolo. 
The proposed suggestion is both a space used theoretically to prepare the project affront to this question, with the development of modalities dwelling of end-of-life period, with contemporary (or past) terms that occur (or have occurred); on the other hand, it is a critical space in relation to the necessary conditions for aging well (including the admit of values and experiences, to build and challenge, in each period of life).

The experience, namely the continuous comparison with learning by doing, has made it possible to relate «55+» population as a task: the surveillance and the control of the said hydroponics machines for the fourth range products, for the human livelihood.

The employment of aging people for their presence and abilities it means mostly to reassess their role and capacities.

\subsection{Italia 2090, super-urban: how?}

Verona has become a centre for «field research» on some of its own conformations: out-posts on roman Postumia, placed at the base of pre-Alpine mountains and Lessinia mountains, woven in the winding relationship with its water, at odds with the open-field beyond the Walls, limited by the growth of the last. In this land, before the $11^{\text {th }}$ century agricultural conversion, everything was lowland forest: this frontier established where and when to settle, by linking and restricting guidelines, survival possibility, collective organization. Then the building of landscape has radically transformed this relationship: today some remnant of lowland forest remains as circumscribed wood. As a part of government territory, the continuous relate to soil as not replicable «resource» has conducted to the reflection about available modalities to contrast this shortage: the answer turned up by the past use of the soil when all was lowland forest. The strategy of «return to forest» was one of the one put in place by the Republic of Venice, for helping the naval production in Arsenal. In the same way, when it was necessary to «build countryside» (namely, to supplant the forest for building agricultural fields) an instrument called «ronco» was used. Hence there is the name of the practice «building countryside». The implemented operation in this research is formerly and operationally opposite: it has built a forest. The theorical practice and the operating strategy led to the project: re-build a vegetal basement in continuity with the original lowland forest, as to continue its history, conditions, settlements, not for a purely romantic fascinating, but mainly for real findings. This new forest is related to the settlement built of Verona as a collective space, as it was with the Comunalia forest: a geometric grid establishes the dimensional relationship, the angle and the inclination it follows the right direction intuited by Cenomans, confirmed by the subsequent constructions, this the project of a forest, this Super-Landscape.

\section{Conclusion}

\subsection{Ecology as project}

In the near future, as it is now known, the confidence in the population increase of Planet Earth brings along with some reflections linked to the questions of density and volume. The increase will not be just the number of inhabitants (demographic crisis) [15], but likely, the necessary food to feed, the produced trash, the data used for communication, the necessary space for welcome all, the administrative regulation, the gap between the wealth and poverty. Those questions concern the building of space. The drafting of tight and multiple bureaucracies (but also counter-productive and contradictory) is the pure expression of this urge. This pressing need to «restrict» the despotism of the individual* («I do what I want, I am not willing to give up my freedom»), by promoting a limitation among all the alternatives («among those restricted at disposition, I chose this way»), clearly and openly declaring that 
the problem is not to dwell the planet, but how people have dwelled and how, probably, they will. In short, the aim is to take time-proof durable measures (precisely sustainable) to allow the existence of human race on Earth: to govern the interaction between a human and habitat, through the project. To describe this, borrowed from biology, we use Ecology [16, pp. 3-9], which means real design and planning (which alternative is the refuse of project and planning, see $\left.\left\langle{ }^{*}\right\rangle\right)$. Ecology is planning of resources and spaces - what allow us to dwell. However, before the promotion of ecological «instrumental» - and so purely/exclusively technological, it should be productive to analyze the question as an anthropological fact: it is not about the use of technological instruments as patch, but to mean modalities and goals necessary for dwelling, updated to times we live in and times we are called to live. The project itself is an ecological manifestation, always interposed as a buffer (or broker) between a human and environment, without an expiration date (how long is the project ex-novo?): architectures surviving us have adapted to different habits, referring to ethic through aesthetics. Thinking about the «livelihood energetic» as pure technologies' application means to answer in a superficial way: it couldn't be the temporary patch for the problem that will provide us with the solution; but rethink those goals according to necessities which they exist and to figure out how the projects should develop without distorting. How those ethic necessities will be translated in esthetic? Will ecology and project become synonyms of «...»? [17, p. 348]. Italia 2090, choosing project's rules, tried to react to those questions.

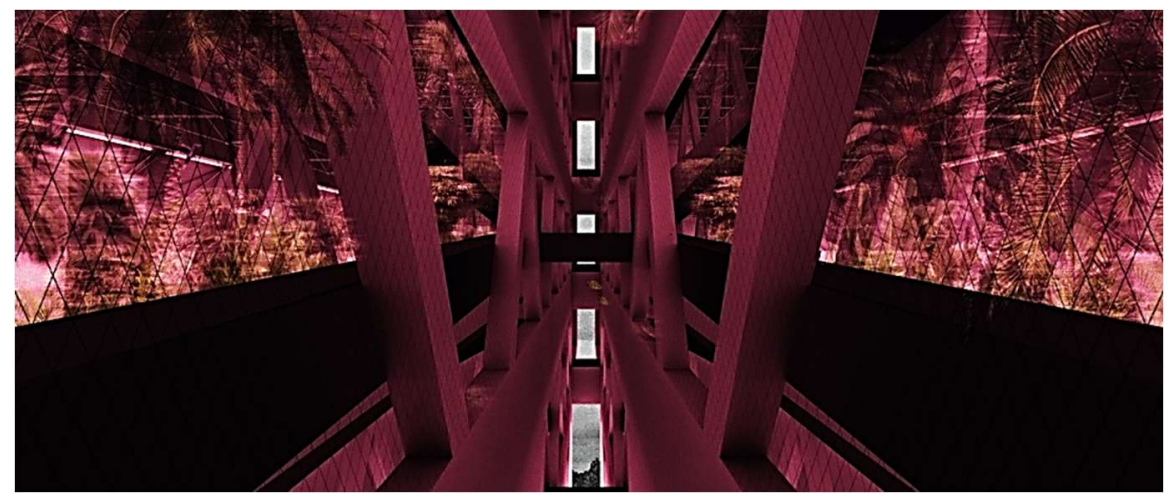

Fig. 17. Inside the tower: Double variation system, see 3.2.

This paper summarizes the results of a wide research, began in November 2019, by Prof. Michelangelo Pivetta (School of Architecture, University of Florence) and PhD. Vincenzo Moschetti (IUAV) that found response through papers, conferences and lectures. This share of methods and the time spent with them provided me with the (just starting) tools that I needed for this research, hoping there would be more.

The author sincerely acknowledges collaboration with Michael Amery (South Africa, 1982), whose paintings were used to make the collages called Fig. 7 and Fig. 8.

The author would like to thank the reviewers for the constructive feedbacks.

\section{References}

1. B. Stanojević (edited by). Free School is Free Space/Serbian Pavillion at 16. International Architecture Exhibition, Museum of Applied Art, (2018).

2. J. Bridle. New dark age: Technology at the end of the future, NERO, (2019).

3. B. Bogdanović. Citissary/Gradoslovar - taken by «Machine or hand» (1956), s.n. (1982).

4. B. Colomina. X-Ray Architecture, Lars Müller Publishers, (2019).

5. Le Corbusier (trans. by P. Knight, E. Levieux, D. Coltman). The Radiant City, Orion Press (1967); first ed. Le Corbusier, La Ville Radieuse, L'Architecture d'aujourd'hui, (1933). 
6. Le Corbusier. Vers Une Architecture, Longanesi, (2013). First ed. (1973).

7. D. Scott-Brown, R. Venturi, S. Izenour. Imparare da Las Vegas. Il simbolismo Dimenticato Della Forma Architettonica, Quodlibet (2010). First Ed., Learning from Las Vegas, MIT Press, (1972).

8. R. Koolhaas, Delirious New York. The Monacelli Press (2016). First ed. (1997).

9. C. Roskam. Inventing the Rural: A Brief History of Modern Architecture in the Countryside, Architectural Design 86, 4 (2016).

10. L. e O.M. Ungers. Kommunen in Der Neuen Welt 1740-1972, Kiepenheuer \& Witsch, (1972).

11. AA. VV. School in Zurich by Christian Kerez, Detail 6, (2020).

12. H. Leistikow. Die Wohnung für das Existenzminimum (The Dwelling for Minimal Existence), Frankfurt Am Main Englert \& Schlosser, (1930).

13. G. Mastrigli (edited by). Superstudio. Opere 1966-1978, Quodlibet, (2016).

14. AA. VV., Italy is One of The Aged Countries of the World: Increasing Singles and The Living Costs in Big Cities, in «La Stampa» (28 december 2017), online source, https://www.istat.it/it/files/2013/10/Asi2017_stampa.it_.pdf

15. R. Burdett, D. Suddjic, (edited by). Living in the Endless City, Phaidon, (2011).

16. AA. VV. Editorial, San Rocco|Ecology 10, (2014).

17. AMO, Rem Koolhaas. Countryside, A Report, Guggenheim Taschen, (2020).

18. Vesper 3, Nella Selva|Wildness, Quodlibet, (2020).

19. M. Petranzan, G. Neri (edited by). Franco Purini - La Città Uguale, Il Poligrafo, (2005).

20. P.V. Aureli. Il progetto dell'Autonomia. Politica e Architettura Dentro e Contro il Capitalismo, Quodlibet, (2016).

21. D.J. Haraway. Manifesto Cyborg. Donne, Tecnologie e Biopolitiche del Xorpo, Feltrinelli (2020). First Ed. (1991).

22. S. Schneider (trans. By G. Malafarina). Artificial You. L'intelligenza Artificiale e il Futuro della Tua Mente, Il Saggiatore, (2020). 